\title{
BISSU YANG ENGGAN MEMBISU Proses Encountering Islam dan Kebugisan
}

\section{Oleh: Syamsurijal Ad'han." "}

\begin{abstract}
77 ii5 article is derived from my own experience living with bissu community in Pangkep last year. I could not say that my research was a pure research. Ijust lived with them, tried to learn to each other, between me and the bissu community

This article aims to reveal the encountering process of Islam with one of the representations of Buginese culture: Bissu, a local community in South Sulawesi. In old days, Bissu was spiritual figure of old Buginese believed to descend to middle earth together with Batara Guru. Since long time ago, Bissu has led the ritual ceremony of the community and the kingdom, before finally a majority of Buginese people embraces Islam. However, in small part of Buginese community, Bissu remains their spiritual leader. Islam and this small part of Buginese culture, since their early encounter, have filled each other. No domination. Bissu has never kept quiet. They always play their negotiation role. Islam, on the other hand, emerges with his kind face, although sometimes, particularly in current times, this process of encounter is in tension.
\end{abstract}

Key words: Islam, Bissu, Negotiation, Acomodation, Encountering

\section{PENDAHULUAN}

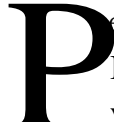

ergulatan (encountering) Islam dan budaya lokal telah berjalan sejak Islam pertama kali diturunkan di tanah Arab. Ajaran dan nilai Islam yang berasal dari langit mengalami pergulatan yang intensif dengan kebudayaan Arab saat itu. Penggunaan bahasa Arab, sebagai media Allah berkomunikasi dengan bangsa Arab saat itu, salah satu bukti proses pergulatan tersebut.

\& Penulis adalah Peneliti Balai Penelitian dan Pengembangan Agama Makassar. 
Syamsurijal Ad'han

Khalil Abd Karim, sejarawan kontemporer Islam saat ini, memaparkan satu gagasan yang menarik tentang Syariat Islam. Ia menunjukkan bahwa hampir sebagian besar dari ajaran Syariat sudah memiliki akar historisnya di tanah Arab. Haji, shalat, shalat jumat, penghargaan terhadap bulan tertentu dengan berpuasa, bahkan beberapa bentuk hudud dan jinayat temyata sudah ada dalam tradisi masyarakat pra Islam. Dengan demikian Syariat Islam tidak turun dengan bentuk yang betul-betul baru, justru ia bisa menapak pada konteks budaya dan historisitas bangsa Arab saat itu.

Kenyataan bahwa Islam bila ingin dikembangkan harus mengalami pergulatan dengan kultur setempat, disadari betul oleh para penganjur Agama Islam di Nusantara. Sunan Kalijaga (1443), salah satu wali dari wali songo, menyampaikan Islam lewat pewayangan, Demikian halnya dengan Syekh Abdurrahman Singkel (1615-1693) dalammenulis kitab Mir'ah al-Thulab dia menimba dari Ahkam al-Sultaniyah sekaligus juga menimba dari tradisi nusantara. Di Sulsel kita kenal Datuk ri Tiro, Sayyid Jamaluddin al-Khusaini (1320), Pallipa Putewe di Pinrang, dan juga Sayyed Jalaluddin diTakalar, mereka semua tidak pernah meminggirkan tradisi dalam menyebarkan agama tapi justru merangkul tradisi dan mendialogkannnya dengan ajaran agama. ${ }^{3}$

Di Sulsel sendiri proses dialog dan pergulatan antara Islam dan kebudayaan lokal adalah sesuatu yang lazim. Dalam satu ungkapan dinyatakan:

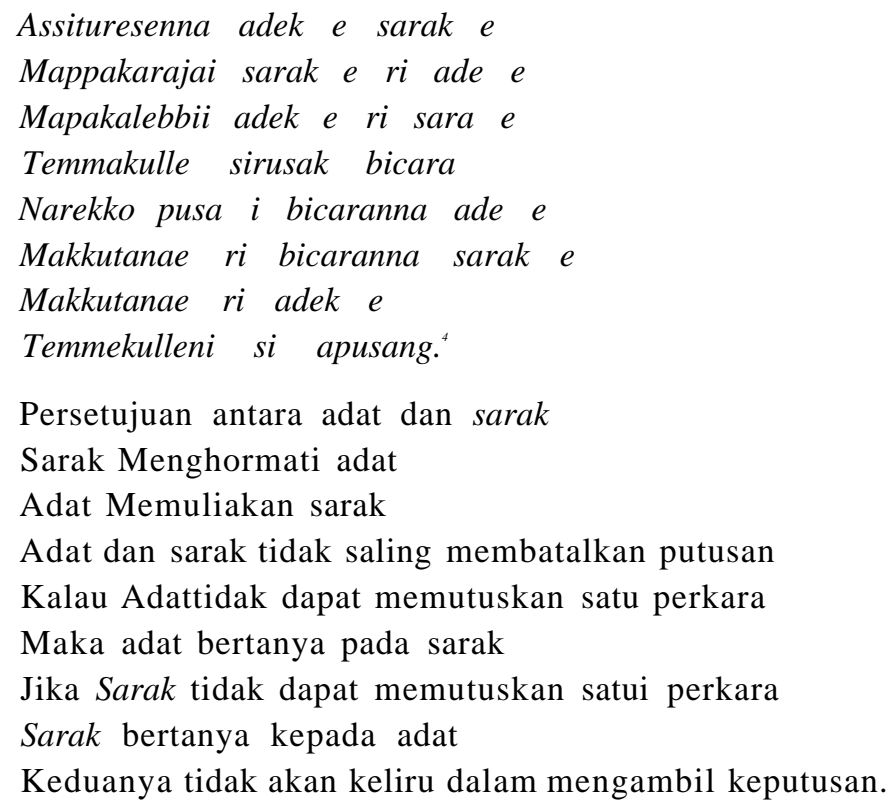


Proses pergulatan antara Islam dan kebudayaan lokal di Sulsel sampai saat ini masih bisa disaksikan di beberapa komunitas. Salah satunya adalah komunitas $\wedge$ ssu yang ada di kabupaten Pangkep Sulsel. Bissu yang merupakan ahli spritual !; ;rajaan dan masyarakat bugis tersebut sampai saat ini dalam praktek hidupnya sehari-hari, menunjukkan proses pergulatan antara Islam dan kebudayaan bugis kuno yang mereka anut. Fokus tulisan ini mencoba melihat lebih jauh pergulatan tersebut. Dalam proses ini ada beberapa hal yang diperhatikan, di antaranya proses negosiasi, akomodasi dan juga proses benturan-benturan yang berupa kontestasi dan resistensi. Disaat yang sama, tulisan ini juga akan menunjukkan pentingnya proses dialog antara Islam lokal dengan Islam pesantren untuk menghindari benturan yang mengarah pada konflik.

Adapun permasalahan yang akan diangkat dalam tulisan ini antara lain: 1). Bagaimana proses perjalanan Bissu di Bugis, khususnya Sigeri? 2). Bagaimana proses Islamisasi pada komunitas Bissu dan respon balik mereka? 3). Bagaimana proses encountering berlangsung antara Islam dan komunitas Bissu?

\section{TEMUAN DAN PEMBAHASAN}

\section{Sigeri-Pangkep; Babak Baru Kehidupan Bissu}

"Ketika tengah hari itu cuaca gelap gulita, taufan dan badai turun. Puang Matowa Bissu dari Lae-Lae, We Salareng dan We Apanglangi, kepala Bissu dari Ware dan Luwu turun ke bawah bersama perlengkapannya, taufan dan badai pun reda".

Itulah sekelumit versi kedatangan pertama bissu di dunia tengah ini. Bissu dalam bahasa bugis di artikan sebagai orang suci yang berakar kata dari "Bessi" atau suci. Demikian dikatakan suci sebab seorang bissu tidak haid, tidak berpayudara dan tidak berdarah. Sementara bissu yang di gambarkan oleh antropolog perancis Matthes bahwa dinyatakan sumber kedatangannya dari Raja Luwu yaitu Batara Guru anak sulung dari Raja Agung di Kayangan yang turun ke bumi (Tumanurung). Dia turun dalam sebatang bambu dan ia keluar dan terasa asing dari penduduk. Kekurangan ini ditutupi dengan bersatunya We Nyili Timo, saudara peremuan dewa mereka yang bangkit dari lautan. Dengan gadis-gadis cantik yang berdiam di Kayangan dan bumi yang fana, barulah kehidupan yang pertama dimulai. Mitos ini dimulai dengan keputusan sepasang dewata terpenting yang memerintah di dunia atas (Datu Patoto' dan Datu Palinge') dan sepasang dewata terpenting yang berkuasa di dunia bawah (Guru ri Selleng dan Sinua Toja) untuk mendiami dunia antara (bumi) agar manusia 
Syamsurijal Ad'han

dapat menyembah dan melayaninya. Maka Batara Guru, putra sulung Datu Patoto' dimasukkan ke dalam bambu. Sebagai to manurung pertama, dia turun ke bumi, memberinya bentuk dan menyebarkan jenis tumbuhan dan hewan pertama. Ketika turun di Luwu', dia segera berpuasa dan bertapa. Kemudian, mengikutlah hamba-hamba, para permaisuri, rakyat dan bahkan istananyapun, semuanya diturunkan dari dunia atas. Lalu sebagaimana yang telah dijanjikan padanya, sepupu satu kalinyaWe'Nyili', putri GururiSelleng, munculkemudian dari air (dia merupakan to tompo' pertama) untuk menjadi permaisurinya yang terpenting. Dengan demikian bagian terpenting silsilah dalam mitos ini sudah disahkan. Berbagai macam peristiwa mulai dari mitos ini sudah disahkan. Berbagai macam peristiwa mulai dari sekarang diceritakan secara berturutturut, berlangsung hingga tujuh keturunan.

Puang Matoa Saidi sering mendefinisikan identitas bissu sebagai "urane majjiwa makkunrai, tengurane toi temmakunraitoF (laki-laki yang berjiwa perempuan, tapi bukan laki-laki juga bukan perempuan). Bisssu adalah pendeta masyarakat bugis kuno, posisinya sebagai penyambung (pengkomunikasi) antara masyarakat bugis dengan dewata yang dilafaldzkan dalam bahasa to riolo. Bissu memegang peran penting disetiap seremoni adat di kerajaan sebab mereka adalah pelayan raja, dan juga sebagai pengabdi di masyarakat. Dalam seremoni seperti memulai tanam padi, panen sampai menempati rumah baru, bissu memiliki otoritas sebagai "orang pintar" yang mendoa dan memohon berkah dari dewata dengan beberapa ritual abbisungan (ritual bissu). Bissu memeiliki puang matoa atau puang toa sebagai pemimpin. Komiitas ini mempunyai istana yang disebut sebagai arajange dan ditugaskan untuk menjaga arajang (benda pusaka).

Komunitas bissu hampir ada di semua daerah bugis di Sul-Sel. Bissu ada dihampir semua tempat di Bugis karena la telah menjadi bagaian integral dari kosmologi masyarakat bugis. Saat ini bissu masih bisa kita temukan di Bone, Wajo dan Soppeng. Namun saat ini yang paling eksis adalah Bissu yang berada di Segeri Kec. Segeri Kab. Pangkep.

Awal kedatangan komunitas bissu di daerah dikisahkan dalam sebuah kisah rakyat yang berkembang di Bone dan Sigeri. Konon Raja Bone lagi bersedih karena bajak kebesaran Bone tiba-tiba lenyap secara misterius. Ini pertanda bahwa malapetaka kelaparan akan menimpa kerajaan Bone. Beliau segera memerintahkan 40 orang bissu mencari bajak keramat tersebut. Beliau berpesan jangan kembali sebelum menemukan dan membawa pulang pusaka tersobut. Pada perjalanan pencarian pusaka tersebut, ternyata bajak keramat tersebut kemudian 
ditemukan di Segeri. Tetapi malang bagi nasib para bissu pencari, sebab masyarakat setempat tidak mau mengembalikannya ke Bone. Karena takut kembali ke Watampone, maka para bissu tersebut memilih menetap di Segeri sambil menjaga bajak yang dianggap sebagai arajang Segeri hingga kini. Sumber lain meyatakan arajang dan bissu beserta tarinya berada di Segeri sejak Abdul Wahab Latenri Sessu Petta Loloe' ri Segeri menjadi raja di Segeri pada tahun 1805 - 1835. La Tend Sessu adalah putra dari La Tenri Leleang, Raja Tanete ke-14. Arajang berbentuk rakkala (bajak sawah) tersebut diganti dan penggantinya diambil dari Gunung Lateangoro Segeri. Sejak itulah arajang Segeri di rawat oleh Bissu dan ditempatkan pada rumah khusus yang disebut bola arajang. Aturan dan anggaran pemeliharaannya ditetapkan oleh raja Segeri secara turun temurun. ${ }^{\circ}$

Segeri adalah salah satu kecamatan di Kabupaten Pengkep. Kecamatan Segeri sendiri, terdiri atas beberapa wilayah seperti dalam tabel berikut:

Luas Wilayah dan Jumlah Penduduk pada Kelurahan dan desa Kecamatan Segeri Kab. Pangkep Tahun 2004/2005

\begin{tabular}{|c|l|c|c|}
\hline No & Kelurahan/Desa & $\begin{array}{c}\text { Luas Wilayah } \\
\text { (Km2) }\end{array}$ & $\begin{array}{c}\text { Jumlah } \\
\text { Penduduk } \\
\text { (jiwa) }\end{array}$ \\
\hline 1 & Bontomatene & 16,72 & 4.881 \\
2 & Baring & 37,52 & 3.314 \\
3 & Parenreng & 9,48 & 3.127 \\
4 & Segeri & 4,21 & 4.072 \\
5 & Bawa Salo & 3,99 & 2.484 \\
6 & Bone & 6,36 & 2.386 \\
\hline & Jumlah & $\mathbf{7 8 , 2 8}$ & $\mathbf{2 0 . 2 6 4}$ \\
\hline
\end{tabular}

Data dari: pemprovsulsel.go.id

Di kampung inilah para komunitas bissu masih bisa di jumpai, mereka dikesehariannya ada yang beperan sebagai indo hotting (perias pengantin) ada juga sebagai petani. Mereka berada di tengah masyarakat yang terkenal religius. Apatah lagi saat ini, pemda pangkep telah menelorkan beberapa perda Syariat Islam untuk diberlakukan di daerahanya. Akan tetapi komunitas bissu tetap menatap masa depan mereka dan aktif berada di arajang sebagai istana yang harus mereka pelihara yang sesekali masyarakat disekitar datang untuk bersilaturahmi. Pemda pangkaep sendiri sebenarnya punya hubungan yang dekat dengan komunitas ini, sebab komuntas bissu telah menjadi langganan disetiap 
even yang diadakan bahkan ikon budaya pangkep di even regional maupun -oanal bahkan internatioinal.

Sekalipun bissu ini adalah komunitas yang sangat di hormati oleh masyarakat hususnya pada masa kerajaan, namun pada masa selanjutnya mereka - a banyak mengalami perlakuan yang kuarang simpati dari kalangan rawan dan pemerintah. Kedatangan Islam dan bergantinya sistem an di Sul-sel sangat mempengaruhi keberadaan para bissu ini. Bahkan kalangan agamawan dan pemerintahan melakukan tindakan refresif : mereka. Menurut data Halilintar Latief, seorang antropolog sulsel an bahwa ada beberapa faktor yang mempengaruhi penghancuran munitas bissu ini yaitu, faktor internal dan faktor eksternal. Penyebab-penyebab terdiri dari faktor eksternal dan faktor internal komunitas Bissu itu sendiri. Salah satu faktor eksternal yang utama adalah perubahan sistem kenegaraan, dari sistem kerajaan menjadi negara kesatuan. Peranan raja yang berwibawa, kharismatik dan berpengetahuan luas tentang adat-istiadat sekarang digantikan oleh peranan seorang camat yang masa jabatannya relatif terbatas di suatu daerah. Demikian pula akibat memudarnya peranan lembaga-lembaga adat, sangat terasa pula pada komunitas Bissu di Segeri. Pada masa pemerintahan kerajaan Bugis, seluruh pembiayaan upacara dan keperluan hidup komunitas Bissu diperoleh dari hasibsawah kerajaan.?

Dengan melemahnya sistem adat maka otomatis sistem pemerintahan modern berkembang dengan fungsi-fungsi hirarki pemerintahan. Kedudukan seorang amat sangat berpengaruh di derah, sehingga setiap keputusan-keputusan yang dikeluarkan akan banyak berdampak pada aktivitas sosial masyarakat. Demikian halnya dengan komunitas Bissu ini, kekuasaan kini di pegang oleh lembaga pemerintahan kecamatan, terlebih lagi sistem politik orde baru yang hegemonial semakin memperparah posisi komunitas bissu. Pada masa inilah transisi posisi bissu terjadi. Pada saat itu, arajang yang menjadi istana dari pada Bissu kini tidak terurus lagi akibat tidak jelasnya pengelolaan internal yang juga dikut dicampuri oleh pemerintah kecamatan. Sebab sebelumnya, bissu mendapatkan biaya untuk pemeliharaan serta kegiatan bissu di arajang berasal dari sumbangan para bangsawan, dermawan serta masyarakat. Selain itu, komunitas bissu juga disedekahkan tanah sekitar 5 Ha dari raja segeri yang bernama Puang Mallongi. Dari tanah itulah, komunitas bissu bisa memanfaatkan untuk keperluan arajang dan juga keperluan ritual abbisungan. Pengolahan sawah dan hasilnya dibagikan masing-masing kepada: jennang (30 Are), pa'puik-puik (30 Are), pa'genrang (dua orang, masing-masing 30 Are), 
pa'dau' (penggembala kerbau upacara, 30 Are), pakkani tekko (pembajak sawah, 30 Are), Puang Lolo (30 Are), dan sisanya untuk Puang Matowa Bissu.

\section{Kedatangan Islam dan Negosiasi Baru yang Dimainkan para Bissu}

Kedatangan Islam di Sigeri hampir bersamaan dengan diterimanya Islam secara resmi di Gowa-Tallo. Islam sendiri Sampai ke Gowa-Tallo diperkirakan sekitartahun 1546-1565 pada saat raja Gowake-16Tunipalangga. Raja Tonijallo sendiri sudah mendirikan mesjid untuk kalangan orang melayu di Mangalekana. Sekalipun demikian menurut Mattulada dua kerajaan besar yang kembar ini secara resmi memeluk agama Islam pada abad 16, tepatnya pada tanggal 9 November 1607. Kita kemudian kenal kerajaan kembar Goa dan Tallo inilah sebagai sumberdari penyebaran agama Islam. (Mattulada 1997:20-21). Memang ada perbedaan pendapat tentang kapan pastinya Islam masuk ke Makassar secara resmi. Diperkirakan oleh Spelman sekitar tahun 1603 (Notitie van speelman/catatan spelman; 1669) ini disepakati oleh F.W.Stapel (Het Bongais verdrag; 1922) atau oleh Matthes (Makassarsche Cherestomathic;lS83)dan Crawfurd (History of the Indian Archipelago; 1820) pada tahun 1605. seorang peneliti lain Rouffaer dengan bersandar kepada Makassarsche Historien menunjuk tahun 1607, sebagai tahun masuknya Islam. Perbedan ini dilukisakan dengan cukup detail oleh Noorduyn dalam Islamisasi di Makassar. ${ }^{8}$

Setelah kerajaan Gowa-Tallo memeluk Islam secara resemi, daerah-daearah lain seperti di Sigeripun mulai memeluk Islam. Kedatangan Islam di Sigeri ini menjadi cerita tersendiri bagi Bissu, yang merupakan komunitas yang selama ini konsisten dengan tradisi Bugis-Kuno.

Awal-awal kedatangan Islam, tidak menjadi problem yang pelik bagi komunitas ini. Disamping karena Islam dalam awal-awal perkembangannya mengedepankan pendekatan tasawwuf yang bisa akomodatif dengan kepercayaan lokal, juga Islam saat itu dijalankan dengan negosiasi kultural oleh para penganjurnya. Islam misalnya tidak berdiri sendiri, tapi lebur dalam sistem Pangederreng. Pangederreng ini mengatur tatanan kehidupan bermasyarakat di Bugis-Makassar. Unsur Islam masuk dalam sistem ini disebut dengan sara '."

Perkembangan selanjutnya dari proses Islamisasi ini mulai bermasalah. Bermula dengan gerombolan DI/TII yang menganggap kegiatan para bissu ini adalah satu kegiuatan yang musyrik dan khurafat. gerombolan lantas melakukan serangan terhadap komunitas ini. Mereka membakar berbagai peralatan upacara para bissu, bahkan melakuakn pembunuhan kepada para bissu yang dianggap 
tidak mau bertobat. Inilah masa yang dinggapa bissu sebagai masa hitam dalam sejarah komunitasnya. Gerombolan yang yang dipimpin Kahar Muzakkar ini menghancurkan semua sendi-sendi komuntas lokal tanpa terkecuali.

Pemerintahan Orde baru sendiri pada tahun 1965 melakuakn satu operasi terhadap para bissu ini dengan asumsi bissu ini adalah bagian dari PKI. Operasi yang kemudian dikenal sebagai operasi toba (oporasi taubat) tidak hanya menghancurkan berbagai peralatan para bissu namun juga menangkapi para bissu dan dipaksa bekerja keras. Para bissu ini juga dipaksakan untuk berubah menjadi laki-laki yang sesungguhnya. "Operasi Toba" (Operasi Taubat) yang gencargencamya terjadi pada tahun 1966 inilah sehingga upacara Mappalili mengalami kemunduran, upacara-upacara bissu tidak lagi diselenggarakan secara besar-besaran. Para Bissu bersembunyi dari ancaman maut yang memburunya. Masyarakat tidak lagi peduli akan nasib mereka, karena sebagian dari mereka memang mendukung gerakan "Operasi Toba" tersebut. Sebagian masyarakat yang bersimpati kepada para bissu, hanya tinggal diam tanpa bisa berbuat apa-apa. Namun ketika masyarakat menuai padinya, ternyata hasilnya memang kurang memuaskan sehingga beberapa masyarakat beranggapan hal tersebut terjadi karena tidak melakukan upacara Mappalili. ${ }^{10}$ Dengan kesadaran itulah beberapa di antara mereka menyembunyikan bissu yang tersisa agar tidak di bunuh dan agar upacara mappalili dapat dilaksanakan lagi. Bissu-bissu yang selamat itulah yang masih ada sekarang ini. Kini jumlah mereka yang tersisa di Kabupaten Pangkep tidak lebih dari duapuluh orang saja. Padahal untuk melakukan sebuah upacara mappalili yang besar, jumlah bissu minimal harus berjumlah empatpuluh orang (bissu pattappuloE)."

Pada waktu kondisi semacam itu para bissu terpaksa menghentikan berbagai kegiatan-kegiatan ritual mereka seperti upaca mappalili dan upacara masongka bala. Kalaupun ada yang tetap melakukan acara-acara tersebut harus dengan cara sembunyi-sembunyi.

Pada masa tahun 1980-an sampai 90-an, kekerasan fisik terhadap bissu ini relatif berkurang, namun stigma terhadap mereka tetap berlangsung. Mereka masih tetap mengangap bissu adalah orang-orang yang menyalahi kodrat dan melakukan tindakan yang musyrik bahkan mereka menganggap bahwa kalangan bissu telah kafir. Disinilah bissu harus memainkan negosiasi baru agar bisa tetap eksis di Sigeri.

Dalam satu kesempatan saat melaksanakan ritual pada acara lepas nazar yang diadakan oleh Haji Nawir pada tanggal 1-3 September 1999, para bissu yang hadir dalam ritual itu tidak mengenakan pakaian adat seperti biasanya. Pakaian adat yang serupa dengan pakaian putri-putri kerejaan zaman dulu itu 
dilemarikan untuk sementara. Dalam upacara itu para bissu justru berpakaian seperti para haji. Mereka berserban dan berpakain putih-putih. Puang Matoa, sebelum Puang Matoa Saidi saat ini bahkan melaksanakan haji. Saidi sebagai puang matoa saat ini dalam keseharainnyajuga senantiasa mengenakan kopiah hitam dilengkapi dengan surban putih yang disungkupkan diatas kopiahnya.

Tidak hanya negosiasi simbolik yang mereka lakukan, para Bissu juga membangun konsep-konsep kecalabai-an (konsep tentang waria) yang selama ini dipandang miring, tidak hanya kalangan agamawan tapi juga masyrakat umum. Para Bissu menyatakan bahwa Bissu adalah calabai tapi tidak semua calabai adalah bissu. Lantas mereka membagi calabai dalam beberapa tingkatan ada yang disebut sebagai calabai tunngke'na lino, paccalabai dan calabai kedokedonami. Calabai tungke'na lino adalah calabai tingkat yang paling tinggi, mereka adalah calabai yang dirahmatai oleh Yang Maha Kuasa itulah sebabnya calabai yang seperti ini terkadang disebut dengan guru. Calabai seperti ini sejak lahir sekalipun berkelamin laki-laki tetapi wataknya sudah meyerupai perempuan. Bissu menurut mereka adalah calabai pada tingkat ini. Sedangkan pa'calabai adalah laki-laki yang menyerupai wanita yang dapat berhubunagan secara ganda, mereka dapat berhubungan dengan laki-laki dan sekaligus dapat berhubungan dengan perempuan. Secara biologis kategori calabai yang kedua ini adalah lakilaki yang mempunyai naluri terhadap sesama laki-laki tetapi juga punya naluri sexualitas terhadap perempuan, ini sangat berbeda dengan kategori yang pertama karena calabai tungke'na lino hasratnya terhadap perempuan memang sama sekali tidak ada. Terakhir adalah yang disebut dengan calabai kedo-kedonami yaitu mereka yang hanya meniru gaya para calabai.

Dengan membangun konsep seperti ini, para bissu ingin menunjukkan bahwa calabai tidak semua harus dimasukkan dalam kategori negatif dan karenanya hams disingkirkan agama. Ada calabai justru merupakan kodrat alam dan sudah suratan takdir Tuhan. Seakan mereka mempertanyakan pantaskah pada kelompok calabai tungke'na lino ini dipersoalkan menyalahi kodrat, padahal mereka sudah ditakdirkan seperti itu.

Konsep semacam ini, nampaknya cukup ampuh untuk meredakan stigma terhadap identitas gender para bissu ini. Hal ini terbukti dalam kesempatan dialog dengan kalangan pesantren yang di mediasi oleh LAPAR-Desantara. Dalam dialog di pesantren DDI Mangkoso ini, argumen para Bissu mengenai identitas mereka dengan membagi tingkatan calabai itu cukup ampuh meredakan pertanyaan kalangan pesantren yang cukup menyudutkan.

Memang dalam meniti kehidupan ini, tradisi bissu mengalami berbagai 
saling mengingatkan, merefleksi tingkah laku dan moralitas masing-masingkarena menurut komunitas passongka bala (kelompok sosial yang melakukan massongka bala) ritual tahunan ini selain untuk mendoakan keselamatan bagi seluruh mahluk bumi, juga dijadikan momen untuk saling menganjurkan kepada kebaikan (dalam Islam biasa disebut amar ma'ruf nahi munkar).

Dua ritual ini disatukan dalam satu upacara. Prosesi sakral ini juga dipimpin oleh dua pemimpin spiritual, yaitu imam kampung dan para bissu. Dalam mitologi bissu, massongka bala terkait dengan proses diutusnya manusia (bissu) oleh Dewata (Tuhan) turun ke bumi untuk memulai membangun peradaban baru (manusiawi) dan itu terjadi bertepatan dengan tahun baru Hijriyah. Itu sebabnya dalam pelaksanaan ritual massongka bala posisi bissu sangat strategis; ritual ini dianggap kurang afdal bila tidak dipimpin/diawali oleh bissu. Sejakalipun bisa juga dipimpin oleh sanro wanuae.

Masyarakat Islam yang acap kali mengikuti dua kegaiatan ini secara bersamaan lalu memberi makna sebagai salah satu model keberagamaan di tempat mereka. Disini kita bisa menyaksikan bagaimana komunitas bissu dan para pengikutnya mencoba membumikan tradisi Islam dalam tradisi yang mereka miliki. Mulai dari menamakan perayaan satu suro itu dengan mappeca sure sampai dengan menyandingkan bahkan meleburkannya dengan masongka bala yang ditimba dari tradisi mereka.

Sepintas, mungkin kita akan mengatakan proses ini sebagai satu singkretisme yang sembrono. Namun bila kita amati perjalanan bissu dan pergulatannya dengan ke Islaman dari awal tadi, maka nampaklah ini sebuah model dialog yang ditata dengan penuh kesadaran. Mereka tetap sadar bahwa Islam adalah satu ajaran yang memiliki nilai yang luhur dan bisa berlaku universal, namun disaat yang sama mereka juga yakin bahwa keluhuran nilai-nilai Islam ini bisa diterjemahkan dan dibumikan melalui tradisi yang mereka miliki.

Komunitas bissu membangun pertemuan antara yang lokal dan yang universal bukan sebagai pertemuan yang saling mengungguli dan menghancurkan, seperti yang dibayangkan Rudyard Kipling dalam The Ballad of East and West: "When two strong men stand face to face though they come from the ends

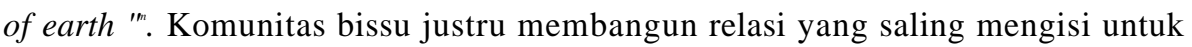
membangun ruang hibriditas. Mengembangkan Islam yang komplementer dengan tradisi, bukan Islam yang suplementer. Maka kiranya dalam konteks semacam ini, tidaklah salah bila Puang Matoa Saidi pernah berucap: "sellenna ugi'E tenniai selleng ara' tapi selleng ugi' mitto" (Islamnya orang bugis bukanlah Islam Arab, tapi memang Islam yang khas Bugis). 
Syamsurijal Ad'han

\section{PENUTUP}

Perjumpaan para bissu dengan ajaran Islam ini tidak hanya menunjukkan kepada kita bagaimana komunitas lokal bisa beradaptasi dengan kultur dan nilai baru yang masuk pada mereka. Tapi proses ini sekaligus menegaskan posisi Islam sebagai agama rahmatan lil alamin yang akomodatif dengan berbagai kultur lokal yang ada.

Islam yang justru dipaksakan pada komunitas-komuntas tertentu, justru akan menimbulkan benturan yang acap kali berbuah kekerasan, sesuatu yang justru ditolak oleh sifat kerahmatan dari Islam itu sendiri. Karena itu proses syiar Islam pada masa-masa yang akan datang seharusnya mampu memahami realitas kultural masyarakat, khususnya masyarakat lokal yang telah memiliki berbagai keyakinan. Realitas itu tidaklah mesti ditekan, namun sebaliknya proses syiar Islam harus bisa bergelut di dalamnya.

Proses perjumpaan tradisi bissu dengan ajaran Islam ini juga menunjukkan bagaimana sebuah model baru keberagamaan Islam yang merupakan buah dari proses encounterning. Model keberagamaan yang baru ini, bisa kita katakan sebagai varian dalam keberlslaman kaummuslimdi Bugis. Varian keberagamaan ini, tentu menunjukkan perbedaan, yang kadang mencolok, dari model Islam mainstreem, namun hal itu harus diyakini sebagai bagian dari pemaknaan spritual masyarakat Islam. Pada tataran tertentu, kadang spritual semacam ini sulit ditemukan rujukannya dalam teks-teks otoritatif, tapi seperti kata Jack Goody spiritualitas tidaklah ditemukan pada teks tapi pada pengalaman penganutnya, dan disitu berkelindang antara hasil apresiasi teks dengan kebudayaannya.

Pada akhirnya Islam dalam mengembangkan ajarannya memang harus bisa mncumbu tradisi dan tidak meminggirkannya. Dengan cara seperti ini ajaran Islam bisa lebih kaya dan mampu membaca realitasnya dengan lebih baik. Pada sisi yang lain proses ini bisa meminimalisir kemungkinan terjadinya konflik atas nama agama. [*]

Catatan Akhir:

${ }^{1}$ Penulis adalah peneliti pada Lembaga Advokasi dan Pendidikan Anak Rakyat (LAPAR) Sulsel dan staff peneliti pada Balai Litbang Agama Makassar.

${ }^{2}$ Khali! Abdul Karim. 2002. Hegemoni Quraisy: Agama, Budaya, Kekuasaan (terj M. Faishol), Yogyakarta: LKiS.

${ }^{3}$ Sebenamya tiap agama yang menginginkan untuk eksisdi satu tempat hams mampu berdialog dengan kultur setempat. Dalam sejarahnya proses dialog antara ajaran agama dan budaya setempat juga terjadi pada agama Kristen. Philip van Akkcren dalam studinyayang menawan menggambarkan 
mengenai "gereja pribumi" di Jawa Timur (kini dikenal sebagai Gereja Kristen Jawi Wetan, GKJW). Dimana Conrad Laurens Coolen sebagai tokohnya berhasil mendialogkan antara ajaran kristen dengan tradisi komunitas Ngoro di Jawa Timur. Yang lainnya dapat disebut pula Kiai Sadrach Surapranata, orang yang sering dijuluki (walau mungkin dia sendiri tidak setuju) sebagai "Rasul Jawa" (Partonadi, 2001). Dia berhasil menyampaikan kristen dengan cara dan lewat kebudayaan Jawa. Karena itu pengikutnya dengan bangga dan penuh kesadaran memilih nama bagi mereka sendiri sebagai "Golongane Wong Kristen Mardhika". Lihat lebih lanjut Trisno S, Susanto, "Diseberang Dewi Sri dan Kristus; Dapatkah Lokalitas Bicara" dalam Ahamad Baso.2002. Plesetan Lokalitas; Politik Pribumisasi Islam, Jakarta: Desantara., h. 113-123

‘ Mattulada. 1985. Latoa: Suatu Lukisan Analisisi terhadap Antropologi Politik Orang Bugis.Yoyakartu: Gajah Mada University Press., h. 155

' Lihat Kren; R.A. 1 La Galigo. 1989. Yogyakarta : Gadjah Mada University Press., h. 34. Pada bagian lain kisah itu, dikisahkan bahwa Puang Matowa dari Lae Lae adalah satu-satunya Bissu yang diturunkan dari langit.

"Halilintar latif dalam makalah Bissu; tradisi trantsvetites shammans Bugis.Makalah, 2002

"Ibid.

${ }^{8}$ Sebelum itu menurut Noorduyn dalam kronik Gowa diceritakan bahwa Karaeng Gowa ToNi Jallo telah bersahabat baik denghan raja-raja Melayu, nbahkan dikatakan ia tertarik dengan ajaran Islam yang dipeluk oleh raja-raja tersebut dan bahkan ingin memeluknya. Kejadioan ini terjadi sekitar tahun 1565-1590 maka beberapa pendapat mengatakan Islam sudah diterima sejak tahun ini. Noorduyn sendiri melihat ada kekeliruan dalam catatan Speelman, menurutnya itu kemungkinan kekliruan tulis, yang sesungguhnya 1605 tetapi ditulis 1603. Selanjutnyalihat J.Noorduyn. 1956. Islamisasi Makassar dari judul asli De Islamisereing van Makassar dalam B.K.I., jilid 112., h.247-266

' Pada awalnya di masyarakat Bugis- Makassar, Pangedarreng ini terdiri dari empat hal yaitu $A d e^{\prime}$ kebiasaan masyarakat yang telah menjadi norma dan nilai, rapang memperbandingkan keputusan hukum dengan hukum yang telah ada sebelumnya, Wicara yaitu semua hal yang berhubungan dengan masaalh peradilan, Wari' dalam Latoa disebut sebagai kemampuan untuk membedakan antara hak dan kewajiban. Setelah kedatangan Islam maka pangederran ini ditambahkan lagi satu unsur yaitu Sara' yaitu semua hal yang berkaitan dengan soal keagamaan dlam hal ini Islam. Mattulada. 1985. Latoa: Suatu Lukisan Analisisi terhadap Antropologi Politik Orang S;(gw.Yoyakarta: Gajah Mada University Press., h. 374

${ }^{10}$ Dahulu masyarakat Segeri percaya apabila tidak melakukan tradisi Mappalili, maka akan datang suatu petaka.

"Salah satu bait mantera dalam bahasa bissu (bahasa dewata atau basa to rilangi'), yakni sessukeng menyebutkan "empat puluh dewata" (de'wata patappuloE). Dalam hal ini angka empat puluh dianggap sebagai angka "sempuma" anggota perkumpulan Bissu. Angka ini juga ada hubungannya dengan empat puluh dewata yang lahir hanya dari mani Hawa sendiri, yang kemudian tersebar di atas bumi di dalam lautan dan di atas langit, dapat menerangkan banyaknya dewadewa yang kedudukannya tidak begitu penting dalam kisah La Galigo, yang segenerasi dengan Datu Patoto. Tentang air mani Hawa yang serupa dengan kelahiran bintang-bintang yang dianggap sama dengan mahluk hidup. Beberapa di antaranya adalah Worongmporong (bintang tujuh), Eppang (secara harfiah "si pincang") yang kemungkinan besar "bintang pagi tohok", dan Tanra Tellu (bintang tiga). Jenis-jenis makhluk pertama yang memenuhi lautan, permukaan bumi, angkasa raya, juga lahir pula dari air mani Hawa. Mungkindalam hal ini ada hubungannya dengan penciptaan jenis tumbuhan dan binatang pertama dari air mani Hawa. 
Syamsurijal Ad'han

\begin{abstract}
${ }^{12}$ Bhaba menjelaskan. Mimicry is thus the sign of a double articulation; a complex strategy of reform, regulation and discipline, which appropeiates the Other as it visualizes power. Mimicry is also sign of the inappropriate, however, a difference or recalcitrance which coheres the dominant starategic function of colonial power, intesifies surveillance, and poses an immanent thereat to both "normalized" knowledges and disciplinary powers. Lihat Homi Bhabha.1997. "Of Mimicry and Man": The ambivalen of Colonial Discourse", dalam Frederick Cooper dan Ann Laura Stoler (eds), Tensions of Empire: Colonial Cultures in a Bourgeois World. Barkeley: University of California Press., h. 152

${ }^{13}$ Rudyard Kapling menceritakan bagaimana hubungan antara timur dan barat sebagai dua etentitas yang tidak bisa ketemu. Pertemuan keduanya ibarat hanya pertemuan dua laki-laki kuat dan bila terjadi hanya akan mengabarkan tentang hancurnya (masa penghabisan) dunia. Tentu saja hubungan antara Agama resmi dan agama lokal atau dalam konteks ini Islam dengan Tanah Toa Kajang bisa saja seperti yang dibayangkan Kapling mengenai pertemuan antara barat dan timur tadi lihat Rudyard Kipling. 1990, "The Ballad of East and West" dalam Harold Coward, Derrida end Indian Philosophy. New York; University of New York., h. 15
\end{abstract}

\title{
DAFTAR PUSTAKA
}

Abdul Karim, Khalil .2002. Hegemoni Quraisy: Agama, Budaya, Kekuasaan (terj M. Faishol), Yogyakarta: LKiS, 2002

Bhabha, Homi K. 1997. "Of Mimicry and Man": The Ambivalen of Colonial Discourse", dalam Frederick Cooper dan Ann Laura Stoler (eds), Tensions of Empire: Colonial Cultures in a Bourgeois World, Barkeley: University of California Press.

Coward, Harold. 1990. Derrida end Indian Philosophy. New York; University of New York.

Kipling, Rudyard. 1990, "The Ballad of East and West" dalam Harold Coward, Derrida end Indian Philosophy. New York; University of New York.

Kren, R.A. 1989. / La Galigo. Yogyakarta: Gadjah Mada University Press.

Latif, Halilintar. 2002. Tradisi Trantsvetites Shammans Bugis. Makalah.

Mattulada. 1985. Latoa: Suatu Lukisan Analisisi terhadap Antropologi Politik Orang Bugis.Yoyakarta: Gajah Mada University Press.

Noorduyn, J. 1956. Islamisasi Makassar diterjemahkan dari judul asli De Islamisereing van Makassar dalam B.K.I., jilid 112

Susanto, Trisno S. 2002. "Diseberang Dewi Sri dan Kris tus; Dapatkah Lokalitas Bicara" dalam Ahamad Baso, Plesetan Lokalitas. Politik Pribumisasi Islam, Jakarta: Desantara. 